\title{
PRÁTICAS AVALIATIVAS NO CONTEXTO DA FORMAÇÃO INICIAL DE PROFESSORES: UM OLHAR SOBRE O ESTÁGIO SUPERVISIONADO
}

\author{
Ana Priscila de lima Araújo AzeVedo \\ lucinalva Andrade Ataíde de Almeida \\ Carla Patrícia Acioli Lins \\ Universidade Federal de Pernambuco (UFPE), Recife, Pernambuco, Brasil
}

\begin{abstract}
Resumo: $O$ presente artigo se insere nas discussões sobre formação inicial de professores, no qual se objetivou uma aproximação das práticas avaliativas realizadas no contexto das atividades do estágio por estudantes sem experiência docente do curso de pedagogia de uma instituição pública de ensino superior do agreste pernambucano, analisando, ainda, se e como as memórias relativas às práticas avaliativas presentes em sua escolarização e formação acadêmica podem influenciar essas práticas. A partir do movimento discursivo dos sujeitos, trilhamos o percurso teórico-metodológico embasado na Análise do Discurso (ORLANDI, 2010). Os resultados apontam para o entendimento de que as memórias se constituem como experiências importantes para mobilizar práticas avaliativas ao longo do estágio supervisionado.
\end{abstract}

Palavras-chave: Práticas avaliativas. Estágio supervisionado. Formação Inicial de Professores. Memórias.

\section{NOTAS INTRODUTÓRIAS}

Este artigo se insere no âmbito das discussões sobre formação inicial de professores, discutindo como os estudantes em formação inicial (re) configuram práticas avaliativas a partir das atividades vivenciadas no estágio no curso de pedagogia. Pensamos que refletir sobre a formação inicial de professores implica também pensar sobre as atividades práticas que são propostas e vividas no contexto escolar. Nesse sentido, o estágio se constitui na possibilidade de imersão no cotidiano da docência e não nos restringimos a pensá-lo a partir da ênfase dada no confronto entre a teoria e a prática, sobretudo porque nesse espaço-tempo o/a estudante pode se deparar com os desafios dos processos de ensinar-aprender em suas variadas dimensões.

Assim, objetivamos nos aproximar das práticas avaliativas realizadas no contexto das atividades do estágio por estudantes sem experiência docente do curso de pedagogia de uma instituição pública de ensino superior do agreste pernambucano, analisando 
ainda se e como as memórias relativas às práticas avaliativas presentes em sua escolarização e formação acadêmica podem influenciar essas práticas.

Desta maneira, entendemos o estágio enquanto componente curricular que se configura não como espaço destinado a uma instrumentalização técnica, perspectiva que acaba reduzindo a formação à prática (PIMENTA e LIMA, 2017). Ao contrário da ideia pautada na racionalidade técnica, entendemos o estágio como ponto de partida e, ao mesmo tempo, de chegada da formação docente, pois prescinde da ideia de que, ao se tomar a prática como objeto de estudo, o/a estudante em formação tem a oportunidade de se pensar num constante movimento que envolve (re) criação e reflexão sobre experiências com potencial formativo que ocorrem num espaço no qual se articula universidade e escola básica.

Assim, a partir de suas vivências no estágio supervisionado, o/a estudante pode se (re) inventar e se (re)pensar, sobretudo pela força exercida pelos saberes sobre ser professor, sobre a escola e sobre ensinar-aprender, elementos que são internalizados ao longo tanto de sua escolarização quanto da formação inicial. Com isso, além de ser possível, no estágio, superar a dicotomia entre teoria e prática, nele também há caminhos para superar a ideia de formação que se faz distante da atuação.

Daí porque partimos do pressuposto de que o estágio se constitui num espaçotempo privilegiado para reflexões sobre e na ação, sendo assim teórico-prático, pois se desenrola em uma atividade de conhecimento e da práxis de ensinar. É nessa perspectiva que é entendido como oportunidade de aproximação do estudante com seu campo profissional. Destacamos que essa aproximação entre estudante e campo do exercício profissional é por nós compreendida como aproximação criativa, de rupturas com modelos e práticas incorporadas ao longo da escolarização, enfim, uma aproximação marcada por possibilidades, incluindo a ação-reflexão-ação.

Acreditamos, assim, que as atividades realizadas por estudantes de pedagogia no estágio supervisionado oportunizam pensar sobre os saberes-fazeres expressos no cotidiano da sala de aula. Dessa maneira, nosso trabalho buscou discutir as práticas avaliativas realizadas durante o estágio supervisionado por estudantes de uma instituição pública de ensino superior do agreste pernambucano, procurando ainda estabelecer possíveis relações entre o que os estudantes traziam enquanto aspectos marcantes relacionados à avaliação da aprendizagem no seu processo de escolarização e formação inicial e suas práticas avaliativas realizadas durante o estágio.

Do ponto de vista teórico, apresentamos nossa compreensão acerca de avaliação da aprendizagem ancoradas em autores como Gonçalves (2017), Méndez (2002), Freitas (2009), Marinho, Leite e Fernandes (2013) e sobre formação inicial em autores como Imbernón (2011), Lima (2001), Nóvoa (1988) e Castro e Amorim (2015). Metodologicamente, utilizamos questionários e entrevistas que nos possibilitaram perceber o movimento discursivo dos professores em formação e, a partir desse movimento, trilhamos o percurso teórico-metodológico embasadas na Análise do Discurso (ORLANDI, 2010), o que nos possibilitou analisar os discursos como social e historicamente produzidos, evidenciando tensões no que diz respeito à formação dos professores e à utilização de práticas avaliativas nas práticas docentes realizadas durante o estágio supervisionado. 
As participantes foram selecionadas a partir de questionários e, posteriormente, foram realizadas entrevistas semiestruturadas (SEVERINO, 2007). Foram selecionadas três participantes que aqui apresentamos com os nomes fictícios de Tereza, Joana e Tatiana, sob o critério da não experiência docente, no sentido de ainda não estarem atuando no campo profissional, porém todas já haviam realizado o estágio em educação infantil e em ensino fundamental.

Por fim, esclarecemos que nosso texto foi estruturado considerando primeiramente a relação entre formação inicial e a recontextualização da prática docente. Assim, expomos e buscamos problematizar alguns de nossos dados, especialmente os que sugerem as experiências de avaliação vividas no processo de escolarização e formação inicial das participantes e sobre as formas de avaliar os alunos utilizadas por elas durante a vivência do estágio supervisionado.

\section{A FORMAÇÃO INICIAL E AS POSSIBILIDADES DE RECONTEXTUALIZAÇÃO DA PRÁTICA DOCENTE}

Pensamos a formação de professores segundo Nóvoa (1988, p. 129), para quem "formar não é ensinar às pessoas determinados conteúdos, mas sim trabalhar coletivamente em torno da resolução de problemas. A formação faz-se na 'produção', e não no 'consumo' do saber". A visão trazida pelo autor aponta para a formação tratada numa perspectiva mais crítica e menos instrumental, já que a formação demanda do professor confiança e autonomia, elementos que lhe permita tomar decisões ao longo do exercício da docência.

Entendemos que essa formação mais crítica se dá numa base tríplice (CASTRO; AMORIM, 2015), que considera a relação do sujeito com sua trajetória e com as aprendizagens que constroem por meio de suas experiências, que podem se dar tanto na formação inicial, quanto nos processos que o indivíduo vivencia em sua trajetória de vida. Neste sentido, Moraes (2015, p. 110) afirma que "a ação docente está fundamentada na história coletiva e na experiência individual de escolarização e de profissão, em sentido prático". Assim, entendemos que as experiências que compõem os sentidos do fazer docente emergem tanto da formação quanto da trajetória escolar e das memórias dos estudantes em formação.

Dessa forma, o estágio supervisionado se afirma na perspectiva que o considera um momento de interpretação da realidade e de estabelecimento de relação com a teoria, criando oportunidades de vivências, experiências e aproximações com o cotidiano escolar. Não é a hora da prática, mas, como nos afirma Lima (2001, p. 16), "é hora de começar a pensar na condição de professor como eterno aprendiz, é hora de vislumbrar a formação contínua como elemento de realimentação dessa reflexão". Assim, o estágio se fundamenta na ação-reflexão-ação e não na antiga visão instrumental que o reduzia apenas ao 'como fazer'.

Sob esse ponto de vista, o estágio é um espaço de possibilidades que pode potencializar os saberes da formação, bem como aqueles que envolvem a socialização pré-profissional, pois esse período que antecede a formação inicial de professores consiste em um espaço-tempo de socialização no qual se adquire ideias, por meio do qual também construímos imagens, sentidos e significados sobre a docência, seja na sua escolarização básica ou nas suas vivências em família e demais grupos sociais em que possa estar imerso. Para Imbernón (2011, p. 62), "certos princípios da ação educativa serão 
interiorizadas durante essa etapa escolar, em que se assume determinados esquemas ou imagens da docência", sendo denominado pelo mesmo autor como período de socialização em que se adquire um pensamento pedagógico comum. Esse pensamento, que provém saberes, poderia então ser mobilizado durante a formação inicial na busca de romper com estereótipos que possam ter sido construídos e também no reforço do que possa ser tido como positivo.

Destacamos ainda que a formação inicial se faz na academia, bem como na escola, numa relação dialógica entre teoria e prática, aliadas para subsidiar o professor em formação, trabalhando elementos básicos para o desenvolvimento dos conhecimentos dos quais ele poderá lançar mão em sala de aula, possibilitando a compreensão da complexidade das práticas nela contidas. Concernente a isso, entendemos o estágio supervisionado na formação inicial do professor como elemento preponderante, embora não único, no que se refere à articulação entre os conhecimentos teóricos que advêm da ciência e o saber-fazer, assim como a apreensão do espaço de atuação profissional.

Nesse contexto, ao buscarmos discutir as práticas avaliativas realizadas pelos professores em formação a partir das atividades realizadas no estágio supervisionado, partimos da ideia de que essas práticas avaliativas mobilizadas pelo professor estão inseridas no contexto da prática docente que está relacionada ao fazer direto da sala de aula, assim como nos afirma Gonçalves (2017, p. 29): “[...] entendemos que a avaliação sendo uma prática inerente à prática docente, não poderia ser concebida distanciada do mais importante propósito que fundamenta a prática docente: o ensino-aprendizagem". Desse modo, entendemos que a avaliação está dentro do fazer inerente à prática docente e que pressupõe diversas concepções sobre a mesma, entre elas as que são pautadas na mensuração ou verificação.

Nós, ao contrário, compreendemos a Avaliação da Aprendizagem como possibilidade de assegurar a formação, tanto de quem ensina quanto de quem aprende, num processo de autoformação por parte do professor. Acreditamos que a avaliação possui uma finalidade formativa e nisso concordamos com Méndez (2002, p. 83) quando afirma: "Avaliamos para conhecer quando corrigimos construtiva e solidariamente com quem aprende, não para confirmar ignorâncias, desqualificar esquecimentos, penalizar aprendizagens não-adquiridas". Embasamos, pois, a nossa compreensão de que avaliar está além de examinar, pois seu desenvolvimento deve acontecer de forma sensível por parte do professor, cujo olhar para o aluno deve ser de acolhimento, na busca de diagnosticar os processos que precisam ser melhorados ou acentuados num melhor desenvolvimento do ensino-aprendizagem.

Nesse sentido, trazemos as contribuições de Freitas (2009) quando ele afirma que a avaliação é uma categoria pedagógica polêmica, pois influencia diretamente na vida das pessoas, permite que elas avancem ou regridam na esfera social, valida os conhecimentos e determina quem pode ocupar qual espaço: "Aqui começa a ser jogado o destino dos alunos - para o sucesso ou para o fracasso" (FREITAS, 2009, p. 28), o que denota o caráter da avaliação como processo que não é neutro, mas carregado de sentidos e pautado em objetivos sociais mais amplos, que podem expressar uma visão de sociedade e de escola.

\section{O ESTÁGIO COMO ESPAÇO-TEMPO DE RESSIGNIFICAÇÃO E CONSTRUÇÃO DE SABERES}


Ao tomarmos as práticas avaliativas de professores em formação sem experiência docente do curso de pedagogia como objeto de nossa investigação, buscamos conhecer inicialmente as memórias que emergiam dos discursos desses sujeitos, servindo este movimento como fio condutor para compreendermos essas práticas avaliativas dentro das atividades realizadas por eles no estágio curricular.

Segundo Moraes (2015, p. 110), "compreender as práticas, significa compreender as condições de produção dessas, que são sempre, histórica e socialmente situadas, não por meio de regras explícitas, mas a partir do senso prático do jogo, de jogar o jogo da sala de aula". Assim, não poderíamos pensar as práticas avaliativas dissociadas do processo de formação dos estudantes e de sua relação com a prática docente, realizada, neste caso, dentro do estágio supervisionado.

Ao questionarmos as participantes de nossa pesquisa (a saber, estudantes do curso de Pedagogia, que ainda não apresentavam experiência na docência) de quais experiências relacionadas à avaliação da aprendizagem tinham recordação, percebemos um movimento de rememoração no qual duas participantes, Tereza e Joana, afirmaram respectivamente: "Foi bem complicado, porque assim, era só mais prova, e tinha fichamento também, só que era mais prova objetiva" (TEREZA; ENTREVISTA, 2016). / "Assim geralmente as avaliações que tinham era mais a questão de provas, então a gente passava ou não devido ao resultado dessas provas" (JOANA; ENTREVISTA, 2016).

Nesses discursos podemos destacar aspectos reveladores do que foi marcante em suas trajetórias de escolarização no que tange à avaliação da aprendizagem, desvelando discursos que apontam especialmente para os instrumentos utilizados, neste caso a prova, além de percebermos no discurso de Joana o caráter classificador e sancionador da avaliação que, nesse sentido, se assenta num modelo positivista, pois, segundo Méndez (2002, p. 31), nessa perspectiva, “[...] a aprendizagem éalgo que se pode medir, manipular e, inclusive, prever".

Então, ao pensarmos a prova como instrumento sancionador, estamos dentro de um sistema no qual, segundo Freitas (2003, p. 40), "aprender para mostrar o conhecimento ao professor tomou o lugar do aprender para intervir na realidade". No caso aqui explicitado a avaliação é apresentada apenas como uma ferramenta para descrever se o aluno tem amontoado os conteúdos expostos em sala de aula, num sistema onde o sujeito é apenas um receptor passivo que aceita e acumula informação (MÉNDEZ, 2002).

Apesar disso, compreendemos que, embora a palavra avaliação possua em sua gênese uma associação com valores quantitativos, classificações e hierarquizações (MARINHO, LEITE e FERNANDES, 2013, p. 313), podemos nos embasar numa perspectiva de avaliação que compreenda uma prática de avaliação formativa "concebida como um dispositivo gerador de maior sucesso escolar" (idem, p. 310). Tereza também se refere ao uso exclusivo da prova como instrumento avaliativo, o que para ela é algo negativo, como podemos perceber no extrato do discurso abaixo:

Pra mim matemática sempre foi pra mim foi um peso, até durante as minhas séries iniciais até o fim do fundamental 1 eu tive muita dificuldade porque as provas elas eram muito objetivas e era o único meio de avaliação que a professora utilizava, [...] mas quando era uma matéria que eu gostava e me identificava fluía apesar que era muito objetiva, mas a professora tirava do livro e 
colocava (a questão), o que mais me marcou negativamente foi a prova. (TEREZA; ENTREVISTA, 2016).

Sabemos que há diferentes estratégias das quais o professor pode lançar mão na intencionalidade de avaliar o processo de aprendizagem dos alunos, embora nem sempre essas estratégias sejam usadas, focando apenas a utilização de instrumentos como a prova, o que é confirmado na fala de Tereza. Ainda em relação a esse aspecto de múltiplas possibilidades nas estratégias avaliativas ressaltamos também o discurso de Joana quando afirma:

Eu acho mais interessante o trabalho apresentado, no caso os seminários, eu acho que aprendo mais porque além de eu ter que sintetizar pra mim, eu tenho que saber repassar, então eu acho que nesse processo o seminário é mais construtivo que a prova que é mais uma questão de decorar mesmo e fazer a prova ali e depois eu não sei se eu lembro ou se eu não lembro, posso lembrar ou não lembrar, mas eu acho mais construtivo o seminário do que a prova. (JOANA; ENTREVISTA, 2016).

Contudo, o aspecto que nos chama atenção no discurso de Joana é a presente indicação da memorização como caminho para realizar o que a prova pedia; dito de outro modo, os alunos encontram meios de responder às questões da prova, mesmo que não tenham de fato conseguido construir o conhecimento. Emerge assim, nesse discurso, um processo em que a aprendizagem pode ser considerada como mecânica em que "os novos conhecimentos são memorizados sem interagirem com quaisquer ideias já existentes na estrutura cognitiva" (VALADARES; GRAÇA, 1998).

Por fim, são rememoradas também questões relativas a avaliações informais que, como traz Freitas (2009, p. 24), são as "práticas avaliativas que incidem sobre as ações disciplinares para manter a ordem na sala de aula e na escola, bem como as avaliações de valores e atitudes". A esse respeito destacamos o discurso de Tatiana, quando ela afirma: "tinha a questão do caderno que o professor avaliava, comportamento, eu não posso esquecer que também tinha o comportamento" (TATIANA; ENTREVISTA, 2016).

Pudemos perceber que as estudantes que participaram desta pesquisa apontam como recordação de sua trajetória escolar e acadêmica saberes constituídos que poderão ser mobilizados durante as atividades realizadas no estágio, seja de modo a se aproximar ou se distanciar do que outrora foi vivido. Nesse sentido, destacamos seus discursos sobre como avaliaram os alunos durante o período em que estiveram no campo do estágio.

A respeito das práticas avaliativas realizadas no estágio supervisionado, destacamos o discurso de Tereza, que descreve que a avaliação que desenvolveu “[...] foi contínua, porque, assim, na aula eu falava e esperava eles responderem sobre, aí a avaliação foi se dando ali" (TEREZA; ENTREVISTA, 2016). Quando questionada se houve algum tipo de registro, afirma: "Não, porque não tinha tempo, a gente utilizava somente a observação e a partir daí a gente trabalhava" (TEREZA; ENTREVISTA; 2016).

Ao afirmar que a avaliação se deu apenas por via da observação, a estudante, que anteriormente afirmou ter dificuldades com a prova como instrumento avaliativo, expressa a necessidade de um distanciamento de instrumentos formais na hora da 
avaliação. Isso pode nos indicar a ideia de uma marca negativa em relação à avaliação da aprendizagem que utiliza esses tipos de instrumento, entre os quais geralmente se encontra a prova escrita.

Entendemos que, apesar do momento do estágio ser curto e possivelmente não haver condições para a realização de uma prova, e não é isso que advogamos, a estudante teria possibilidade de lançar mão de outros instrumentos que pudessem lhe oferecer maior sistematização do processo de ensino-aprendizagem, mesmo que a via escolhida fosse a observação.

Esse tipo de observação que a estudante fez uso é uma observação informal, por meio da qual, segundo Melchior (1994, p. 78) "[...] o professor observa sem ter se organizado ou programado para tal". Configura-se como o tipo de observação mais comum na sala de aula e muito útil ao professor, todavia, ainda para a mesma autora, essas observações devem ser complementadas por observações formais que são aquelas que "[...] se realizam de forma sistemática e organizada. Exigem planejamento e instrumentos adequados" (MELCHIOR, 1994, p. 80).

Assim, apesar de serem importantes e úteis, as observações devem ser complementadas, pois por si sós não darão conta do processo de avaliação. Percebemos que não houve nenhuma atividade ou registro do que foi trabalhado, assim nos questionamos se não haveria necessidade de ter uma forma mais sistematizada das respostas obtidas durante o processo avaliativo. Melchior (1994, p. 92-93) ainda reitera que "apesar de sua importância, as observações são insuficientes para o professor acompanhar o desenvolvimento de cada um dos seus alunos, sendo necessárias outras técnicas e outros instrumentos de avaliação".

Ressaltamos que Tatiana, outra participante da pesquisa, também afirmou ter feito observações, contudo explicitou que fez registro dessas observações, apesar de trabalhar com a oralidade. Todavia, quando questionada sobre como se deu a avaliação, sua primeira resposta foi: "A gente não fez, em nenhum momento, prova" (TATIANA; ENTREVISTA, 2016). Percebemos então que seu discurso traz marcas fortes da associação feita entre avaliação e o instrumento específico prova, o que reforça a ideia da memória que associa o processo apenas ao instrumento avaliativo. E ela ainda afirma ter feito uma avaliação diagnóstica de seus alunos no estágio supervisionado.

Como tinha esse problema da leitura e da escrita, a gente trabalhava muito com o que eles falavam e anotava o que eles falavam e o que eles desenhavam, a gente apresentava conteúdos, explicava a eles e questionava o que estava sendo ensinado, mas a nossa forma de avaliação era mais a oralidade, tentava escrever e anotar e instigava eles a falar, porque, como eles não escreviam, a nossa avaliação foi mais na questão da oralidade. (TATIANA; ENTREVISTA, 2016).

Nesse discurso identificamos a presença de um diagnóstico feito a partir da observação que orientou o trabalho da estagiária, então percebemos que alguns alunos apresentavam dificuldade na leitura e na escrita, o que a conduziu a lançar mão de atividades que tivessem como estratégia principal a oralidade. Neste aspecto percebemos a consciência por parte do professor de como o sujeito aprende e a descoberta de uma maneira de ajudá-lo (MÉNDEZ, 2002). 
Salientamos que o discurso de Joana, sobre sua prática avaliativa realizada dentro das atividades do estágio, aponta indícios de uma observação mais sistematizada que levou a estudante a propor uma atividade concreta para os alunos. Afirma ela: "Desde o começo eu percebi que a sala era bem participativa e pra avaliação a gente trouxe algo assim, que trouxesse eles também e não a gente impondo uma avaliação, então teve observação, mas também teve uma atividade em cima do que a gente trabalhou, eles fizeram um mural" (JOANA; ENTREVISTA, 2016).

Entendemos, assim, que a prática docente realizada por essas estudantes, na emergência de ações a serem desenvolvidas em sala de aula, revelam sua reflexão tanto sobre sua própria ação quanto sobre o percurso formativo do qual participaram e participam, apresentando as marcas constituintes desse processo como parâmetros para realização de suas práticas avaliativas, seja para se aproximar ou se distanciar do que foi vivido.

\section{ALGUMAS CONSIDERAÇÕES}

Como resultados de pesquisa apresentamos, a partir do movimento discursivo dos professores em formação, que as memórias relativas ao seu processo de formação, durante toda sua trajetória de escolarização, estão presentes em sua prática docente, se configurando como possibilidades na realização de suas ações no cotidiano da sala de aula, neste caso específico de estudo no tocante às práticas avaliativas realizadas no estágio supervisionado.

A partir do retorno das estudantes em formação às suas memórias, destacamos que as lembranças referentes a uma avaliação pautada na ideia de classificação se configura como algo marcante na construção das ideias e dos sentidos sobre a avaliação e sobre a própria ideia do ser docente dessas estudantes. Isso se reflete nas aproximações e distanciamentos que fazem das práticas vivenciadas em suas trajetórias.

Ao enfatizarem a relação que tiveram com a realização de provas, apresentam-na como negativa e assim se afastam da ideia pautada numa avaliação classificatória, e isso se reflete nas ações realizadas em sala de aula durante a vivência do estágio supervisionado. Já ao destacarem, por exemplo, as observações feitas e registros das mesmas, no que se refere também às atividades realizadas no estágio, se aproximam de uma ideia de avaliação processual da qual rememoram em sua formação inicial.

Frente a isso, podemos inferir que os saberes construídos em suas trajetórias de escolarização e formação inicial são elementos que influenciam suas práticas desde a primeira aproximação com o campo profissional. Assim, não podemos desconsiderar os saberes da socialização pré-profissional, nem sobrepô-los aos saberes construídos na formação inicial, uma vez que temos a possibilidade de dialogar com os diversos saberes no espaço-tempo do estágio, que se apresenta como elemento privilegiado na (re) configuração da prática docente.

As possibilidades às quais nos referimos dizem respeito aos saberes que são mobilizados a partir das memórias desses estudantes que configuram no estágio a busca de aliar os saberes da experiência, que ocorrem não apenas no exercício profissional, mas também a partir da realidade de sala de aula, à vivência dos sujeitos enquanto alunos. 
Assim, quando falamos em saberes da experiência, falamos também de contextos de formação presentes não apenas na realização da prática docente enquanto exercício profissional, mas também na formação de estruturas e saberes mobilizados a partir das vivências dos indivíduos, a partir de sua trajetória de vida escolar e acadêmica.

Artigo recebido em: 30/10/2018

Aprovado para publicação em: 15/03/2019

EVALUATIVE PRACTICES IN THE CONTEXT OF INITIAL TEACHER TRAINING: A LOOK AT THE SUPERVISED INTERNSHIP

ABSTRACT: This article is part of the discussions about initial teacher training, which aimed at an approximation of the evaluation practices carried out in the context of the internship activities by students without teaching experience of the pedagogy course of a public institution of college education in the wild state of Pernambuco, analyzing also, how and if, the memories related to the evaluation practices present in their schooling and academic formation can influence these practices. From the discursive movement of the subjects, we traced the theoretical-methodological route based on Discourse Analysis (ORLANDI, 2010). The results point to the understanding that memories are important experiences to mobilize evaluation practices throughout the supervised stage.

KEYWORDS: Evaluative Practices. Supervised Internship. Initial Teacher Training. Memoirs.

PRÁCTICAS EVALUATIVAS EN EL CONTEXTO DE LA FORMACIÓN INICIAL DE PROFESORES: UNA MIRADA SOBRE LA PASANTÍA SUPERVISADA

RESUMEN: El presente artículo se inserta en las discusiones sobre formación inicial de profesores, donde se objetivó una aproximación de las prácticas evaluativas realizadas en el contexto de las actividades del pasantía, por estudiantes sin experiencia docente del curso de pedagogía de una institución pública de enseñanza superior en el interior de Pernambuco, analizando aún, cómo y si, las memorias relativas a las prácticas de evaluación presentes en su escolarización y formación académica pueden influir en estas prácticas. A partir del movimiento discursivo de los sujetos, atravesamos el recorrido teórico-metodológico basado en el Análisis del Discurso (ORLANDI, 2010). Los resultados apuntan al entendimiento de que las memorias se constituyen como experiencias importantes para movilizar prácticas evaluativas a lo largo de la pasantía supervisada.

PALABRAS CLAVE: Prácticas de evaluación. Pasantía supervisada. Formación Inicial de Profesores. Memorias. 


\section{REFERÊNCIAS}

CASTRO, M. M. C.; AMORIM, R. M. A. A formação inicial e continuada: diferenças conceituais que legitimam um espaço de formação permanente de vida. Cadernos Cedes, São Paulo, vol. 35, n. 95, p. 37-55, jan./abr. 2015.

FREITAS, L. C. Ciclos, seriação e avaliação: confrontos de lógicas. São Paulo: Moderna, 2003.

FREITAS, L.C. [et. Al.] Avaliação educacional: caminhando pela contramão. 2 ed. Petrópolis: Vozes, 2009.

GONÇALVES, C. L. Práticas avaliativas de estudantes-professoras: desenvolvimento da profissionalidade e profissionalismo a partir dos contextos de influência presentes no cotidiano escolar. 2017. 227 f. Dissertação (Mestrado em Educação Contemporânea) Universidade Federal de Pernambuco, Caruaru, PE, 2017.

IMBERNÓN, F. Formação docente e profissional: formar-se para mudança e a incerteza. 9 ed. São Paulo: Cortez, 2011.

LIMA, M. S. L. A hora da prática: reflexões sobre o estágio supervisionado e a ação docente. Fortaleza: Edições Demócrito Rocha, 2001.

MARINHO, P; LEITE, C; FERNANDES, P. A avaliação da aprendizagem: um ciclo vicioso de "testinite". Revista: Estudos em Avaliação Educacional, São Paulo V. 24, n.55, p. 304-334, abr./ago. 2013.

MELCHIOR, M. C. Avaliação pedagógica: função e necessidade. Porto Alegre: Mercado aberto, 1994.

MÉNDEZ, J. M. A. Avaliar para conhecer, examinar para excluir. Porto Alegre: Artmed, 2002.

MORAES, D. Z. O que a escola faz com o currículo de história: o exame dos sentidos do trabalho docente e da lógica das práticas de ensino. In: CATANI, D.B.; GATTI JÚNIOR, D. (Orgs) O que a escola faz? Elementos para a compreensão da vida escolar. Uberlândia: EDUFU, 2015.

NÓVOA, A. A formação tem de passar por aqui: as histórias de vida no projeto Prosalus.In: NÓVOA, A.; FINGER, M. (Orgs). O método (auto)biográfico e a formação. Lisboa: Ministério da saúde, 1988. p. 107-130. 
AZEVEDO, A. P. de L. A.; ALMEIDA, L. A. A. de; LINS, C. P. A.

ORLANDI, E. P. Análise do discurso: princípios e procedimentos. 9 ed.- Campinas: Pontes editores, 2010.

PIMENTA, S. G.; LIMA, M. S. L. Estágio e docência. 8 ed. São Paulo: Cortez, 2017.

SEVERINO, A. J. Metodologia do trabalho científico. 23 ed.- São Paulo: Cortez, 2007.

VALADARES, J.; GRAÇA, M. Avaliando para melhorar a aprendizagem. Lisboa: Paralelo editora, 1998.

Ana Pricila de lima Araújo Azevedo: Mestranda do curso de Pós-Graduação em Educação Contemporânea na linha de Pesquisa de Docência, Ensino e Aprendizagem no Centro Acadêmico do Agreste na Universidade Federal de Pernambuco.

Orcid: https://orcid.org/0000-0001-5245-5814

E-mail: anapriscila_azevedo@hotmail.com

Lucinalva Andrade AtAíde de Almeida: Doutora em Educação pela Universidade Federal de Pernambuco (UFPE). Estudos na área de Educação, com ênfase em Políticas e Práticas Curriculares, atuando principalmente nos seguintes temas: Currículo; Políticas Curriculares; Práticas Curriculares; Práticas de Avaliação; Formação de Professores e Cotidiano Escolar. Orcid: https://orcid.org/0000-0002-3577-1716

E-mail: nina.ataide@smail.com

CARLA PATRícIA ACIOLI LINS: Doutora em Sociologia. Temáticas de interesse: Formação inicial e Continuada de Professores; Processos de Profissionalização de Docentes.

Orcid: https://orcid.org/0000-0001-6941-4656

E-mail: aciolilins.carla@gmail.com

Este periódico utiliza a licença Creative Commons Attribution 3.0, para periódicos de acesso aberto (Open Archives Iniciative - OAI). 